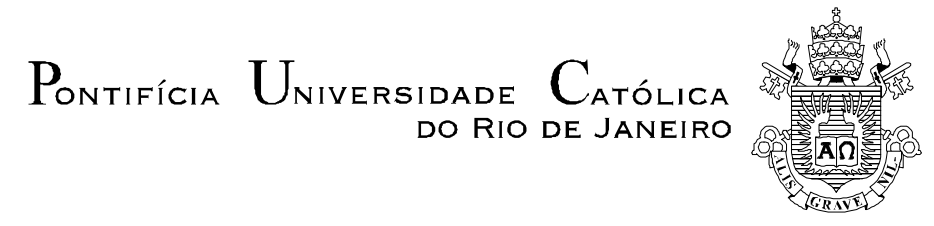

Francisco José Mattoso Paiva

\title{
Proposta de variáveis críticas para o modelo preliminar de apoio à decisão de aquisição de refinarias em novos mercados
}

Dissertação de Mestrado

Dissertação apresentada como requisito parcial para a obtenção do grau de Mestre pelo Programa de PósGraduação em Logística do Departamento de Engenharia Industrial da PUC-Rio.

Orientador: Prof. Nélio Domingues Pizzolato

Rio de Janeiro

Setembro de 2009 


\section{Proposta de variáveis críticas para o modelo preliminar de apoio à decisão de aquisição de refinarias em novos mercados}

Dissertação apresentada como requisito parcial para a obtenção do grau de Mestre pelo Programa de Pós-Graduação em Logística do Departamento de Engenharia Industrial da PUC-Rio. Aprovada pela Comissão Examinadora abaixo assinada.

Prof. Nélio Domingues Pizzolato

Orientador

Departamento de Engenharia Industrial - PUC-Rio

Prof. Luiz Felipe Roris Rodrigues Scavarda do Carmo Departamento de Engenharia Industrial - PUC-Rio

Profa. Fernanda Maria Pereira Raupp Departamento de Engenharia Industrial - PUC-Rio

Prof. José Eugênio Leal

Coordenador Setorial do Centro Técnico Científico - PUC-Rio 
Todos os direitos reservados. É proibida a reprodução total ou parcial do trabalho sem autorização da universidade, do autor e do orientador.

Francisco José Mattoso Paiva

Graduou-se em Engenharia Química na UFRJ (Universidade Federal do Rio de Janeiro em 1986. Cursou Engenharia de Processamento, na Petrobras, em 1987. Atuou na área de Logística por 10 anos, desenvolvendo estudos e projetos na área de Qualidade de Produtos. É docente na Universidade Petrobras, nas disciplinas de Logística, Petróleo e Derivados e Processos de Refino. É coordenador da área de processamento de petróleo e derivados.

Ficha catalográfica

Paiva, Francisco José Mattoso

Proposta de variáveis críticas para o modelo preliminar de apoio à decisão de aquisição de refinarias em novos mercados / Francisco José Mattoso Paiva ; orientador: Nélio Domingues Pizzolato. - 2009.

73 f. : il. (color.) ; $30 \mathrm{~cm}$

Dissertação (Mestrado em Engenharia Industrial)Pontifícia Universidade Católica do Rio de Janeiro, Rio de Janeiro, 2009.

Inclui bibliografia

1. Engenharia industrial - Teses. 2. Fluxos. 3. Globalização. 4. Indústria do petróleo. 5. Novos mercados. 6. Refinaria. I. Pizzolato, Nélio Domingues. II. Pontifícia Universidade Católica do Rio de Janeiro. Departamento de Engenharia Industrial. III. Título. 


\section{Agradecimentos}

A Deus, pelo dom da vida.

Aos meus pais, por todo esforço em propiciar-me os conhecimentos que adquiri ao longo de minha vida.

À minha esposa e filhos, pela compreensão em todos os momentos do desenvolvimento deste trabalho.

A Petrobras, na figura de meus gerentes e colegas de trabalho, que me propiciaram as condições necessárias para o êxito neste trabalho. 


\section{Resumo}

Paiva, Francisco José Mattoso; Pizzolato, Nélio Domingues. Proposta de variáveis críticas para o modelo preliminar de apoio à decisão de aquisição de refinarias em novos mercados. Rio de Janeiro, 2009. $73 \mathrm{f}$. Dissertação de Mestrado - Departamento de Engenharia Industrial, Pontifícia Universidade Católica do Rio de Janeiro.

Em consequência da atuação das empresas de petróleo em um mercado globalizado, uma das etapas do processo de internacionalização destas empresas é a aquisição de refinarias em novos mercados. Destacam-se aqueles em que as oportunidades são mais desafiadoras, como as emergentes economias do Oriente, principalmente a China e a Índia. Se a eficiência de um sistema logístico é crítica para as operações das empresas em seus próprios países, torna-se ainda mais importante para estas operações globalizadas, considerando-se os diferentes ambientes encontrados nos países onde as empresas passam a operar. A tomada de decisão sobre a aquisição de novas refinarias fora de seus países requer o conhecimento dos impactos desta aquisição sobre os fluxos de petróleo e seus produtos entre os mercados, considerando-se os diferentes fatores que atuam sobre estes fluxos. Neste trabalho, por meio de uma pesquisa bibliográfica, estuda-se a proposta da Petrobras em desenvolver uma ferramenta de avaliação do fluxo de petróleo e seus produtos em função da compra de novas refinarias, a ser utilizada no processo de tomada de decisão. Estudam-se as principais variáveis críticas de projeto a serem consideradas no futuro desenvolvimento dessa ferramenta.

\section{Palavras-chave}

Fluxos; globalização; indústria do petróleo; novos mercados; refinaria. 


\section{Abstract}

Paiva, Francisco José Mattoso; Pizzolato, Nélio Domingues (Advisor). Critical variables proposal for a preliminary decision making model of acquisition of refineries in new markets. Rio de Janeiro, 2009. 73 p. MSc. Dissertation - Departamento de Engenharia Industrial, Pontifícia Universidade Católica do Rio de Janeiro.

As a consequence of the performance of the oil companies in a globalized market, one of the steps of the internationalization process of these companies is the acquisition of refineries in new markets. Among them are those where opportunities are more challenging, as the emerging economies of the East, especially China and India. If the efficiency of a logistics system is critical to the companies' operations in their countries, it becomes even more important for these globalized operations, considering different environments of the countries where the companies will operate. The decision on the acquisition of new refineries out of their countries requires the knowledge of the impact of that acquisition on the oil and its products flow through the markets, considering the various different factors that affect them. Based on a literature survey, in this work the proposal for developing a tool for evaluating the oil and its products flow for Petrobras as a function of the purchase of new refineries that will be used in the decision making process is studied. This thesis analyses the main project's critical variables to be considered in the future development of this tool.

\section{Keywords}

Flows; globalization; new markets; oil industry; refinery. 


\section{Sumário}

1 Introdução 11

1.1. Justificativa 11

1.2. Objetivo Principal 12

1.3. Objetivos Específicos 13

1.4. Metodologia de Trabalho 13

1.5. Estrutura do Trabalho 14

2 O processo de internacionalização da Petrobras 16

2.1. A criação da Petrobras 16

2.2. O início da internacionalização 17

2.3. Criação da nova área internacional 18

3 As economias emergentes do Oriente 23

3.1. O crescimento econômico da China 23

3.2. O crescimento econômico na Índia 26

3.3. Efeitos do crescimento no mercado de petróleo 27

3.4. Organização do setor petróleo 29

3.5. Tendência do mercado futuro de óleo e derivados 31

4 Análise da ferramenta de apoio para tomada de decisão na área internacional da Petrobras 33

4.1. Modelo da cadeia de suprimento de petróleo 33

4.2. Descrição da ferramenta 36

4.3. Importância da ferramenta de apoio na tomada de decisão 39

5 Análise das variáveis críticas da ferramenta 43

5.1. Capacidade de Refino $\quad 45$

5.1.1. Conceituação 45

5.1.2. Aplicação 48

5.2. Capacidade de transporte 51

5.2.1. Conceituação 51

5.2.2. Aplicação 54

5.3. Demanda de Mercado 56 
5.3.1. Conceituação

5.3.2. Aplicação 59

5.4. Preço de petróleo e derivados 61

5.4.1. Conceituação 61

5.4.2. Aplicação 63

6 Conclusão 65

6.1. Conclusões 65

$\begin{array}{ll}\text { 6.2. Recomendações } & 67\end{array}$

7 Referências Bibliográficas $\quad 69$ 


\section{Lista de figuras}

Figura 1 - Ativos da Petrobras na Argentina 19

Figura 2 - Localização da Refinaria da Petrobras em Pasadena, Texas 20

Figura 3 - Refinaria da Petrobras em Okinawa e sua área de influência 21

Figura 4 - Carga atual e prevista processada fora do Brasil pela Petrobras 22

Figura 5 - Consumo per capita de petróleo no mundo 25

Figura 6 - Cadeia de suprimento na indústria do petróleo 33

Figura 7 - Fluxo de Petróleo e Derivados entre fornecedores e clientes 35

Figura 8 - Hierarquia de utilização do sistema de informações logísticas 37

Figura 9 - Mapa de acompanhamento dos fluxos de petróleo 39

Figura 10 - Esquema de refino para produção de combustíveis 46

Figura 11 - Movimentação de produtos (milhões de toneladas) 54 


\section{Lista de tabelas}

Tabela 1 - Taxas de crescimento da Índia, 1950-2004 (\% a.a.)

Tabela 2 - Principais consumidores de petróleo, 2000-2008 (milhões de toneladas)

Tabela 3 - Rendimentos de produtos em diferentes perfis de refinarias 48

Tabela 4 - Classificação dos navios conforme seu porte bruto 